\title{
Influence of textile structure on the wearability of printed e-textiles
}

\author{
Abiodun Komolafe, Helga Nunes-Matos, Monika Glanc-Gostkiewicz, Russel Torah \\ School of Electronics and Computer Science, University of Southampton, SO17 IBJ, UK \\ a.o.komolafe@soton.ac.uk
}

\begin{abstract}
To achieve durable printed circuits on textiles, it is necessary to print low-cost polymer films that interface the fabric with the printed circuit. The film smooths the surface of the fabric to enable the printing of thin and flexible conductive films on the fabric. When printed, the thickness of the polymer films can dominate the fabric and limit the flexibility of the printed e-textile. This paper investigates the reduction of the polymer film thickness for printed and wearable e-textiles by controlling the thread count of the fabric using different blends of polyester/silk/cotton fabrics. A $50 \mu \mathrm{m}$ thick polyurethane interface layer with a surface roughness, Ra value of $1.7 \mu \mathrm{m}$ is reported on a $100 \%$ plain weave polyester fabric. The PU thickness is 4 times less than the state of the art and shows more than $80 \%$ reduction in the proportion of interface material to fabric thickness of the printed e-textile. This minimizes the impact of the printed film on the fabric.
\end{abstract}

\section{Keywords-Printed circuits, polymer film, printed e-textiles}

\section{INTRODUCTION}

Printing is one of the main integration methods for incorporating electronics into textiles [1]. This is because printing processes such as screen-printing and roll to roll printing are used regularly in the textile industry to mass produce and integrate a variety of patterns directly onto the textile. However, when conductors are printed directly on textiles [2, 3], the printability and electrical conductivity of the conductor is compromised by the surface roughness and porosity of the textile. Although printing conductors of an average thickness between 20 and $45 \mu \mathrm{m}$ usually overcomes this limitation, these conductors often lack flexibility and durability to withstand the bending stresses that textiles undergo during use [4].

By introducing a polymer film (or an interface layer) between the fabric and the printed circuit, the printability, flexibility and conductivity of the conductor improve. The interface layer, usually printed or laminated on the fabric, smooths the fabric surface and reduces the printed conductor thickness (to typically $\leq 5 \mu \mathrm{m}$ ) [5] as shown in figure 1 . This also reduces the cost of conductive material used during fabrication since these polymers are cheaper than the conductive inks [6]. Examples of polymers used as interface layers include acrylic resin [7], silicone [7], and polyurethane films $[8,9]$.

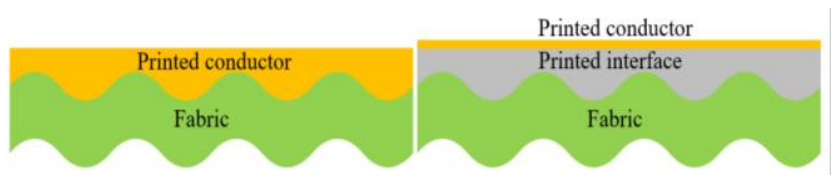

Figure 1: Printed fabric with and without interface layer.

To ensure a printed e-textile remains wearable, it is important that the thickness of the interface layer does not dominate the fabric after printing and compromise the textural comfort of the resulting e-textile. Laminated or heatpressed polyurethanes on fabrics achieve interface layer thickness down to $25 \mu \mathrm{m}$ but the fabric loses breathability during lamination [4] because the laminated film covers the whole fabric area. The film may be laser cut to a circuit layout to improve breathability but this introduces an additional process to the fabrication of printed e-textiles. Printing offers the flexibility of tailoring the interface layer to any circuit layout whilst maintaining breathability of the fabric. Unlike laminated interfaces, printed interfaces ensure that printed e-textiles are fabricated in a single manufacturing process. A screen printed interface layer with an average thickness of $200 \mu \mathrm{m}$ thick polyurethane film for printing strain gauges, heaters, ECG and EMG electrodes on Optic-White A1656 polyester-cotton fabric currently represents the state of the art $[10,11]$. At this thickness, the average surface roughness of the fabric is significantly reduced to less than $3 \mu \mathrm{m}$ However, this interface layer contributes to more than $50 \%$ of the total thickness of the printed e-textile which impacts on the comfort of an e-textile wearer.

This paper furthers the research on screen printed interfaces by optimising the interface layer thickness on nine different blends of polyester/cotton/silk fabrics, listed in table 1. In the approach, the printability and wearability of the etextile is investigated by reducing the thickness of the interface layer to ensure the thickness of the printed fabric is not dominated by the printed film. Reduction in the thickness of the printed film will minimise manufacturing cost by reducing the time, cost and amount of ink used during printing. Surface roughness measurement of the interface layer is also examined to enable good printability of any subsequent devices. This paper also examines the effect of the thread density of the textile (or thread counts) on the thickness of interface layer. This is necessary for fabricating or identifying the fabric that is best suited for printed etextiles.

\section{MATERIAL SELECTION AND SCREEN PRINTING PROCESS}

\section{A. Fabric and ink selection}

Four different commercial woven fabrics and four handmade fabrics were used in this work as shown table 1 . The commercial fabrics are a blend of polyester/cotton fabrics and were supplied by Klopman International [12]. They were primarily chosen because of their different textile properties such as thickness, textile material composition and weave structure. Moreover these are standard fabrics for garment manufacture. 
TABLE I. PHYSICAL PROPERTIES OF FABRIC AND SCREEN PRINTED POLYURETHANE

\begin{tabular}{|c|c|c|c|c|c|c|c|c|c|c|c|}
\hline Fabrics & Supplier & $\begin{array}{c}\text { Material } \\
\text { compositi } \\
\text { on } \\
\text { (polyeste } \\
\text { r/cotton/s } \\
\text { ilk) } \% \\
\end{array}$ & $\begin{array}{c}\text { Weave } \\
\text { structure }\end{array}$ & $\begin{array}{c}\text { Avg. } \\
\text { fabric } \\
\text { thickness } \\
(\mu \mathrm{m})\end{array}$ & $\begin{array}{c}\text { Fabric } \\
R_{a} \text { Value } \\
\quad(\mu \mathrm{m})\end{array}$ & $\begin{array}{c}\text { Avg. } \\
\text { PU } \\
\text { thicknes } \\
\text { s } \\
(\mu \mathrm{m})\end{array}$ & $\begin{array}{c}R_{a} \\
\text { Valu } \\
\mathrm{e} \\
(\mu \mathrm{m})\end{array}$ & $\begin{array}{c}\text { PU- } \\
\text { fabric } \\
\text { thickn } \\
\text { ess } \\
\text { ratio }\end{array}$ & $\begin{array}{c}\text { Avg. PU } \\
\text { thicknes } \\
\mathrm{s} \\
(\mu \mathrm{m})\end{array}$ & $\begin{array}{c}R_{a} \\
\text { Value } \\
(\mu \mathrm{m})\end{array}$ & $\begin{array}{c}\text { PU- } \\
\text { fabric } \\
\text { thickne } \\
\text { ss ratio }\end{array}$ \\
\hline & & & & & & \multicolumn{3}{|c|}{$1^{\text {st }}$ set (standard print) } & \multicolumn{3}{|c|}{$2^{\text {nd }}$ set (optimized print) } \\
\hline $\begin{array}{c}\text { Optic White - } \\
\text { A1656 }\end{array}$ & \multirow{5}{*}{ Klopmann } & $65 / 35 / 0$ & Twill 2x1 & 174 & 17.4 & 192 & 1.7 & 1.10 & 192 & 0.8 & 1.10 \\
\hline Concept & & $65 / 35 / 0$ & Plain & 278 & 27.8 & 175 & 2.8 & 0.63 & 139 & 3.0 & 0.5 \\
\hline Starmaster & & $40 / 60 / 0$ & Twill $2 \times 1$ & 340 & 38.0 & 196 & 1.9 & 0.58 & 218 & 1.5 & 0.64 \\
\hline Spotlight & & $65 / 35 / 0$ & Twill 2x1 & 305 & 24.8 & 174 & 0.9 & 0.57 & 182 & 1.1 & 0.60 \\
\hline Oxford & & $50 / 50 / 0$ & Twill 2x1 & 306 & 33.8 & 163 & 1.3 & 0.53 & 146 & 0.9 & 0.5 \\
\hline IsacordPoly60 & \multirow{4}{*}{$\begin{array}{l}\text { University of } \\
\text { Southampton }\end{array}$} & $100 / 0 / 0$ & Plain & 207 & 20.8 & 214 & 1.3 & 1.03 & 50 & 1.7 & 0.24 \\
\hline IsacordPoly 72 & & $100 / 0 / 0$ & Plain & 223 & 32.1 & 200 & 1.6 & 0.90 & 77 & 2.5 & 0.34 \\
\hline GaddamSilk80 & & $0 / 0 / 100$ & Plain & 161 & 18.6 & 228 & 1.3 & 1.41 & 245 & 2.4 & 1.52 \\
\hline GaddamSilk88 & & $0 / 0 / 100$ & Plain & 172 & 24.1 & 246 & 1.2 & 1.43 & 235 & 1.1 & 1.37 \\
\hline
\end{tabular}

The hand-made fabrics were woven from polyester and silk yarns using a Toika electric hand-loom at the University of Southampton (UoS). The yarn density (or thread counts) of the fabrics was varied to examine its influence on the printed thickness of interface layer. 100\% Polyester fabrics, IssacordPoly60 and IssacordPoly 72 with thread counts of 60 threads/inch and 72 threads/inch respectively were woven. $100 \%$ Silk fabrics, GaddamSilk80 and GaddamSilk88 with thread counts of 80 threads/inch and 88 threads/inch were also woven.

Screen printable UV curable polyurethane ink, FabinkUV-IF-1 supplied by Smart Fabric Inks Ltd was used to print the interface layer. The ink was selected because of its good adhesion and printability on fabrics [5].

\section{B. Screen printing process}

The interface layer was printed on all the fabrics using a DEK 248 semi-automatic screen printer. The textile substrates were initially bonded to an alumina plate to provide mechanical support during printing. Two types of printing was done. For the first set of prints, the standard print parameters for interface layer printing on the state of the art Optic-White A1656 fabric was used []. Four layers of PU paste was deposited on all the fabrics using a screen with an emulsion thickness of $40 \mu \mathrm{m}$. Each PU layer was UV cured for 30 seconds. The thickness and surface roughness of the final PU layer is given in Table 1. All the fabrics had relatively low surface roughness after printing as illustrated in figure 3 with the Optic-White A1656 fabric. For the second set of prints, the number of printed layers was varied until the fabric achieved a visually smooth surface. The printed thicknesses, shown in table 1, were compared with the values from the standard prints. The printed interfaces shown in Figure 2 were tailored to the circuit design for biomedical electrodes within the WEARPLEX project.

\section{SURFACE ROUGHNESS OF FABRICS AND SCREEN PRINTED PU FILMS}

A 2-D Tencor P-11 surface profiler was used to obtain the 2-D surface profile of the initial fabrics and then the subsequently printed PU films on top of those fabrics. The total number of profiled points, $n$ is 10,000 for a profile scan length of $5000 \mu \mathrm{m}$. Using this data, the average surface roughness, $R_{a}$ can be calculated using equation 1 .
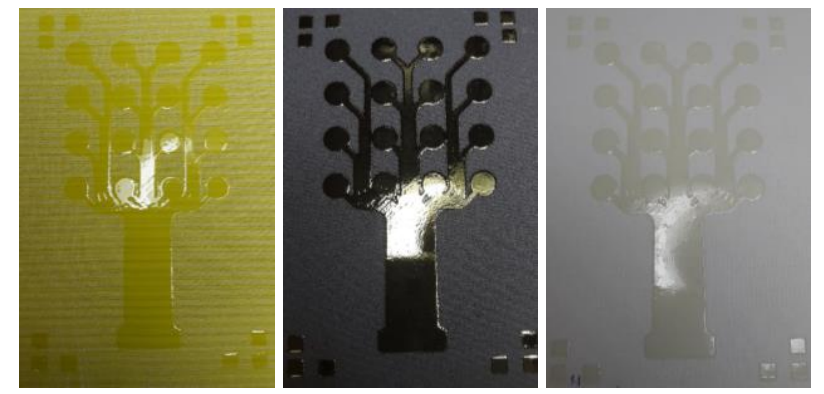

Figure 2: Printed interface patterns for biomedical electrodes using IsacordPoly60, Oxford and Optic White fabrics after 1, 3 and 4 layers of PU prints respectively.

$$
R_{a}=\frac{1}{n} \sum_{i=1}^{n}\left|S_{i}\right|
$$

Where $S_{i}$ is the surface displacement at a profiled point " $i$ ", and " $n$ " is the total number of profiled points. An example measurement contrasting the surface roughness of the Optic-White A1656 fabric and the subsequent printed PU layer is shown in Figure 3. The $R_{a}$ values for all the different fabrics and the screen-printed PU films are shown in Table 1.

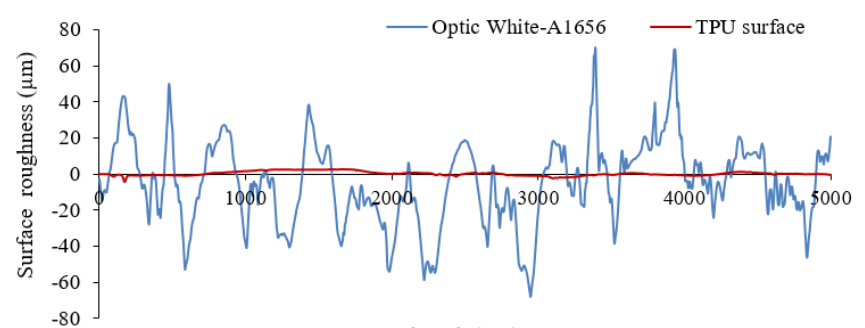

Scan length $(\mu \mathrm{m})$

Figure 3: A comparison of the surface roughness of fabrics and screenprinted polyurethane film.

\section{A. Effect of PU thickness on $R_{a}$ Value}

In general, the screen printed PU films are smooth compared with the surface of the fabric as shown in figures 3 and 4 achieving $R_{a}$ values $\leq 3 \mu \mathrm{m}$. Typically, this level of smoothness is achieved on the Optic White A1656 fabric with an average PU thickness of $190 \mu \mathrm{m}$ as shown in table 1 . To achieve similar smoothness with reduced PU and/or fabric thickness would improve flexibility of the printed 
fabrics and also minimise the influence of the PU on the fabric.

Figure 5 shows that in some cases, there wasn't significant improvement in the $R_{a}$ value for small $(\leq 50 \mu \mathrm{m})$ increments in the PU thickness on the same fabric. This is most likely because the difference between the high and low PU thicknesses for the same fabric is still within the error margin of the screen-printing process. Consequently, to improve the $R_{a}$ significantly, the difference in PU thickness must be more than the thickness variation or tolerances that occur during printing. However, the range of thickness deviation is reflected in this $R_{a}$ measurement because the reference point is the fabric surface and therefore it is still relatively minor compared to the overall thickness of any subsequently printed electronic layers.

Both figures 6 and 7 show that the IsacordPoly72 and IsacordPoly60 fabrics achieve significantly reduced PU thickness with both having a $\mathrm{R}_{\mathrm{a}}<2.5$. The PU thickness for these fabrics are 2.5 and 4 times less than the PU thickness required for the Optic White A1656 fabric respectively. These fabrics also have a low PU-fabric thickness ratio $(<$ 0.5) which minimises the influence of printed PU on the fabric. The Oxford fabric is another potential fabric for limiting the influence of PU on fabric. Although the fabric is almost twice as thick as the A6156 fabric, it shows similar $R_{a}$ with A1656 for half the PU-fabric thickness ratio of A1656.

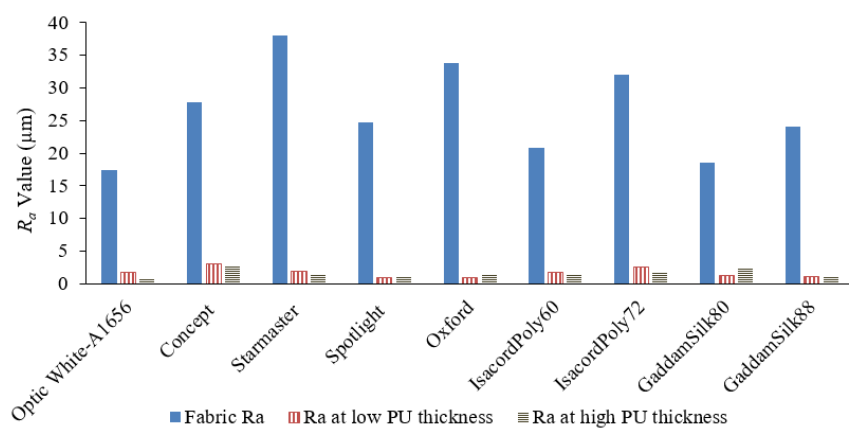

Figure 4: A comparison of the Ra values of printed fabrics at different PU thickness. The high and low thickness values are given in table 5 for each fabric

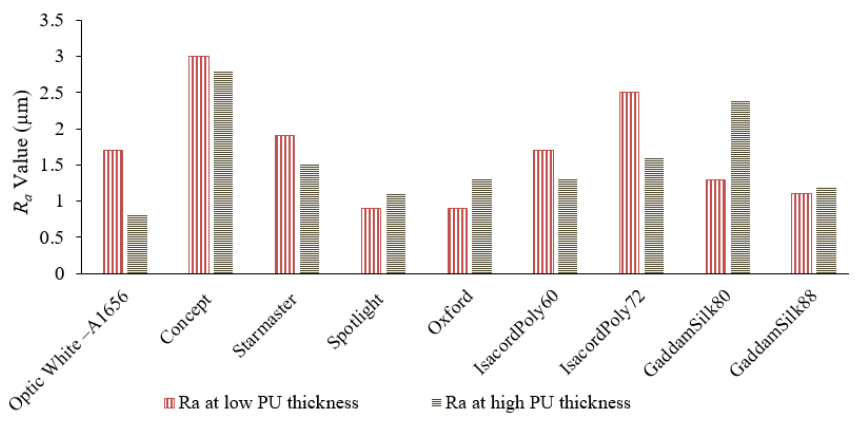

Figure 5: Relationship between Ra value and PU thickness

\section{B. Effect of thread counts on $R_{a}$ Value and the PU-fabric thickness ratio.}

Results shown in figure 4 suggests that the surface roughness also increases with the thread count for the UoS fabrics of material composition. For example, a low $R_{a}$ value is measured for IsacordPoly60 compared the IsacordPoly72 which has a higher thread count. Similar trend is also observed for the GaddamSilk fabrics.
Figure 6 also suggests that a higher PU thickness increases with the fabric thread count however the PU may completely dominate the fabric as is the case with the GaddamSilk fabrics in figure 7 where the PU is thicker than the fabric.

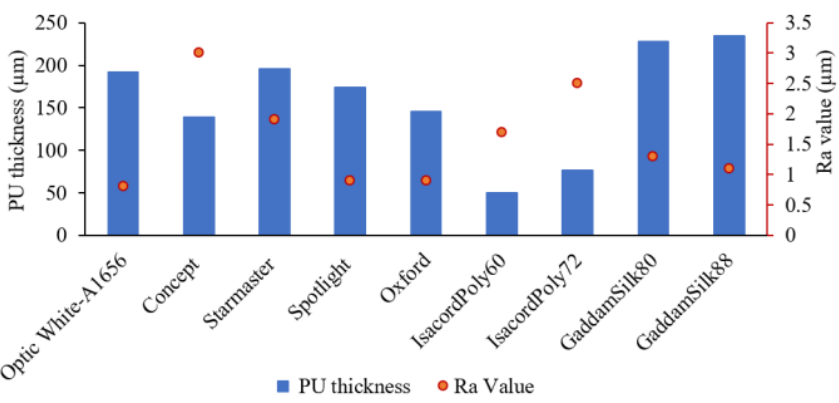

Figure 6: Comparison of the minimum PU thickness on all fabrics with Ra $\leq$ $3 \mu \mathrm{m}$.

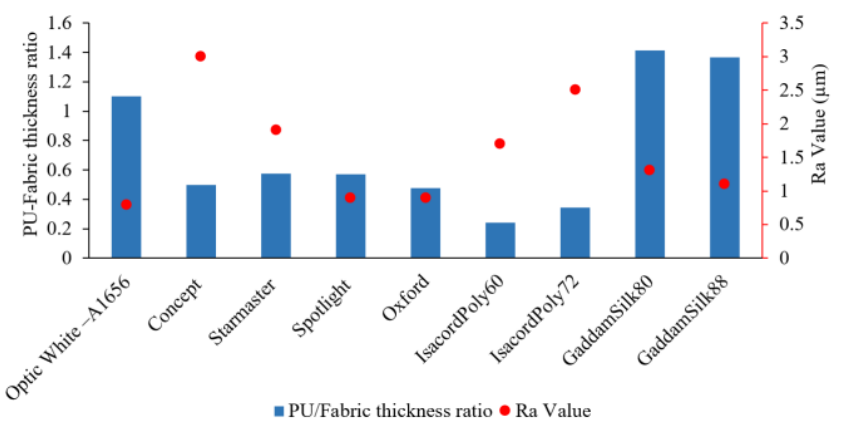

Figure 7: Comparison of the PU to fabric thickness ratios on all fabrics with $\mathrm{Ra} \leq 3 \mu \mathrm{m}$.

\section{CONCLUSIONS}

Printed interfaces are used to level the surface of fabrics to improve the printing of electronic circuits on the textile. This paper reported a $78 \%$ reduction in the state of the art printed PU thickness for the interface layer using fabrics of low thread counts of 60 and 72 threads/inch. A PU thickness up to 4 times less than the current state of the art with similar surface roughness $(0.8$ to $1.7 \mu \mathrm{m})$ were realised on these fabrics. The implication of this for the manufacture of printed e-textiles is the reduction in printing time, cost of the printed ink (as low volume is printed) and reduction in electrical energy required for curing the printed inks.

The fabric thread count is shown to influence the thickness of PU interface layer. The printed interface thickness increases with the fabric thread count. At thread counts greater than 80 threads/inch, results show that the PU thickness becomes greater than the fabric. This can limit the wearability of the printed fabric since it is now dominated by the interface material. A further study into fabrics of a wider range of thread counts would better characterise the printing of interfaces and the best choice of fabrics for printed etextiles.

\section{ACKNOWLEDGMENT}

This work is funded by the WEARPLEX project with a Grant agreement ID: 825339 under the Horizon 2020 EU funding - ICT-02-2018. The data for this paper can be found at DOI: 


\section{REFERENCES}

[1] L. M. Castano and A. B. Flatau, "Smart fabric sensors and e-textile technologies" A review. Smart Materials and Structures, 23(5), 053001

[2] Y. Kim, H. Kim, and H. Yoo, "Electrical characterization of screenprinted circuits on the fabric" IEEE transactions on advanced packaging 33.1 (2009): 196-205.

[3] B. Karaguzel, C. R. Merritt, T. Kang, J. M. Wilson, H. T. Nagle, E. Grant, and B. Pourdeyhimi. "Flexible, durable printed electrical circuits." The Journal of The Textile Institute 100, no. 1 (2009): 1-9.

[4] Komolafe, Abiodun. "Reliability and interconnections for printed circuits on fabrics." PhD diss., University of Southampton, 2016.

[5] A. O. Komolafe, R. N. Torah, K. Yang, J. Tudor, and S P. Beeby, "Durability of screen printed electrical interconnections on woven textiles." In 2015 IEEE 65th Electronic Components and Technology Conference (ECTC), pp. 1142-1147. IEEE, 2015.

[6] P. Gordon, R. Torah, K. Yang, S. Beeby, and J. Tudor. "An investigation into the durability of screen-printed conductive tracks on textiles." Measurement Science and Technology 25, no. 2 (2014): 025006.
[7] I. Kazani, C. Hertleer, G. De Mey, G. Guxho and L. Van Langenhove, "Dry cleaning of electroconductive layers screen printed on flexible substrates", Textile Research Journal, June 2012, pg. 1-8

[8] M. Suh, K. E. Carroll, E. Grant, and W. Oxenham, W, "Effect of fabric substrate and coating material on the quality of conductive printing" Journal of the Textile Institute, 104(2), 213-222, 2013

[9] F. Josue, R. L. Llopis, J. Moreno, J. V. Lidón-Roger, and E. GarciaBreijo, "An investigation into the fabrication parameters of screenprinted capacitive sensors on e-textiles." Textile Research Journal (2020): 0040517519901016.

[10] K. Yang, K. Meadmore, C. Freeman, N. Grabham, A. Hughes, Y. Wei, R., M. Glanc-Gostkiewicz, S. Beeby, and J. Tudor, "Development of user-friendly wearable electronic textiles for healthcare applications." Sensors 18, no. 8 (2018): 2410.

[11] Y. Wei, K. Yang, M. Browne, L. Bostan, and P. Worsley, "Wearable electrical stimulation to improve lymphatic function." IEEE Sensors Letters 3, no. 2 (2019): 1-4.

[12] Klopman International S.r.l., https://www.klopman.com/, last assessed, $9^{\text {th }}$ March 2020 